\title{
Editorial
}

\section{Slow potentials and catheter ablation for AVNRT}

A functional discordance of conductive and refractile properties within atrionodal and AV nodal tissues is thought to be the basis for AV nodal reentrant tachycardia (AVNRT). Contemporary therapy aimed at curing AVNRT without materially damaging normal AV conduction began with surgical AV node modification. ${ }^{1}$ Catheter based techniques with DC shocks and later with radiofrequency energy have been shown to be equally effective. The recognition of the posteriorly placed usual exit site of the slow pathway then led to the evolution of techniques of selective slow pathway ablation aimed at reducing the risk of complete AV block. ${ }^{2-5}$

One approach to slow pathway ablation has therefore been anatomical, with radiofrequency energy sequentially applied to the posteroinferior interatrial septum and, later, if required, to the mid-septum. Published data show that the success rates usually achieved $(>90 \%)$ require a high number of radiofrequency energy applications (range of medians 4-14). ${ }^{34}$

The electrophysiological approach on the other hand uses either retrograde slow pathway mapping or recognition of pathway potentials to guide ablation. ${ }^{5-17}$ As retrograde slow pathway conduction is elicitable only in a minority of patients such mapping is not commonly used in spite of its reported specificity. ${ }^{4}$

\section{Spike potentials}

A spike-like "Asp" potential accompanying a lower amplitude A potential has been noted in the vicinity of the coronary sinus ostium in patients with AVNRT. ${ }^{5}$ These potentials have been shown to reverse their temporal relation during retrograde slow pathway conduction, and Asp to be separately advanced by late atrial premature extrastimuli. In our experience, the activation sequence of this double potential is strictly dependent on the site of origin of the atrial activity and, therefore, indirectly of the retrograde nodal exit. ${ }^{3}$ Such dual atrial potentials (including spike potentials) have been found in $98 \%$ of a group of patients with no manifest AVNRT. ${ }^{6}$

Using the Asp potential as a guide, AVNRT was successfully eliminated in $99 \%$ of patients with a median of two applications of radiofrequency current, without affecting normal AV conduction. Animal studies, however, have shown that Asp-like potentials arise from atrial muscle cells possessing rapid upstroke action potentials.

\section{Slow potentials}

Electrical activity ascribed to the AV node was noted on extracellular recordings in dogs in $1956 .{ }^{8}$ However, it was Scher et al who in 1959 described "slowly developing" potentials from the AV node region in a canine model. ${ }^{9}$
Other contemporaries also described similar potentials in dogs, calves, and pigs (variously termed $\mathrm{N}$ potentials, slow deflections, and nodal hump), and characterised their behaviour in response to vagal stimuli and pharmacological agents. ${ }^{1011}$ In humans such potentials were recorded for the first time in 1969 by Damato et al ${ }^{12}$ and attributed to the compact $\mathrm{AV}$ node. ${ }^{12}$

In the course of studies involving radiofrequency ablation for AVNRT, we described slow potentials recordable during antegrade $\mathrm{AV}$ conduction along the tricuspid valve at the mid and posterior part of the septum - at a significant distance from the anatomic site of the AV node-in 95\% of patients with AVNRT and their previously unreported rate-dependent behaviour. ${ }^{13}$ Radiofrequency energy applied at this site characteristically curtailed the ability of atrial stimulation to prolong critically the $\mathrm{AH}$ interval. The tachycardia was thus rendered non-inducible with a median of two (presently one) applications of radiofrequency energy. Similar potentials were found in $80 \%$ of patients without AVNRT or echo beats.

These low amplitude slow potentials are concealed within or prolong the atrial electrogram, and occupy some or all of the AV diastolic interval. Requiring high amplification $(0 \cdot 1-0.2 \mathrm{mV} / \mathrm{cm})$ and atrial pacing, these potentials are readily recorded as the catheter is withdrawn posteriorly from the His bundle position. They are however absent or difficult to detect in about $20 \%$ of patients. Most importantly, with progressively rapid atrial pacing, these potentials separate from preceding atrial electrograms, decline in amplitude and slope, and prolong in duration, frequently culminating in their disappearance. We believe that slow mid-septal potentials persisting with atrial pacing at the end of AV intervals during antegrade slow pathway activation represent activity of the compact AV node.

Studies in pigs and dogs have shown that similar double potentials with a prominent second low frequency component arise from and around the site of retrograde slow pathway activation (sensitivity $100 \%$ ), and originate in superficial transitional cells with nodal type action potentials. ${ }^{71617}$ Recent evidence suggests that such cells situated in the region of the posterior AV nodal approaches participate in retrograde slow pathway conduction such as during reverse echo beats. ${ }^{14}$ Such slow potentials were also recorded in rabbits along a discrete bundle distinct from the crista terminalis input. ${ }^{18}$

These potentials can, however, persist at the ablation site even after successful slow pathway ablation. Mapping studies consistently describe a rather diffuse distribution of such potentials, suggesting that only in the appropriate anatomic context (the paratricuspid mid-posterior septum) do these potentials represent slow pathway activation. These nodal transitional cells probably also form the 
first defence of the ventricles against an atrial tachycardia, followed thereafter by the compact AV node. As there is evidence that multiple atrionodal connections may exist in the form of a network, the recognition of electrophysiological parameters distinguishing the actively participating slow pathway activation is important. Unfortunately, this is difficult in clinical conditions primarily owing to catheter instability. Also important is the separation of potentials produced by bystander cells/dead end tracts from those produced by cells actively involved in AV conduction.

In the interim, until such distinctions are achieved, we believe that both the anatomic and pathway potential approaches are equally successful and safe, but the pathway potential approach appears more parsimonious.

MICHEL HAÏSSAGUERRE DIPEN C SHAH

Hôpital Cardiologique du Haut-Lévêque, PIERRE JAÏS

Avenue de Magellan, 33604 Pessac Cedex, France

1 Pritchett ELC, Anderson RW, Benditt DG. Reentry within the atrioventricular node. Surgical cure with preservation of atrioventricular conduction. Circulation 1979;60:440-6.

2 Sung RJ, Waxman HL, Saksena S, Juma Z. Sequence of retrograde atrial activation in patients with dual atrioventricular nodal pathways. activation in patients with
Circulation $1981 ; 64: 1059-67$.

3 Haïssaguerre M, Fischer B, Marcus FI, Clémenty J. Role of catheter ablation for treatment of supraventricular tachyarrhythmias. In: Mandel WJ, ed. Cardiac arrhythmias. 3rd edn. Philadelphia: JB Lippincott, 1995: 939-62.

4 Jazayeri MR, Sra JS, Akhtar M. Transcatheter modification of the AV node using radiofrequency energy. Herz 1992;3:143-50.

5 Jackman WM, Beckman KJ, McClelland JH, Wang X, Friday KJ, Roman $\mathrm{CA}$, et al. Treatment of supraventricular tachycardia due to atrioventricular nodal reentry by radiofrequency catheter ablation of slow-pathway conduction. N Engl F Med 1992;327:313-18.

6 Hazlitt A, Beckman K, McClelland J, Wang X, Jackman W. Prevalence of slow AV nodal pathway potentials in patients without AV nodal reentran tachycardia [abstract]. F Am Coll Cardiol 1993;21:281A.

7 McGuire MA, de Bakker JMT, Vermeulen JT, Opthof T, Becker AE, Janse $\mathrm{MJ}$. Origin and significance of double potentials near the atrioventricular node. Correlation of intracellular potentials intracellular potentials and histology. Circulation 1994;89:2351-60.

8 Van Der Kooi MW, Durrer D, Van Dam RT, Van Der Tweel LH Electrical activity in sinus node and atrioventricular node. Am Heart 1956;51:684-700.

9 Scher AM, Rodriguez MI, Liikane J, Young AC. The mechanism of atrioventricular conduction. Circ Res 1959;7:54-61.

10 Sodi-Pallares D, Medrano GA, Bistoni A, De Michelli A. The electrograms of the conduction tissue in the normal dogs heart. Am $\mathcal{f}$ Cardiol 1959;4: 459-63.

11 Pruitt RD, Essex HE. Potential changes attending the excitation process in the atrioventricular conduction system of bovine and canine hearts. Circ the atrioventricular

12 Damato AN, Lan SH, Berkowitz WD, Rosen KM, Lisi KR. Recording of specialised conducting fibers ( $\mathrm{A}-\mathrm{V}$ nodal, His bundle and right-bundle branch) in humans using an electrode catheter technique. Circulation 1969;39:435-47.

13 Haïssaguerre $M$, Gaïta $F$, Fischer $B$, Commenges D, Montserrat $P$ d'Ivernois $\mathbf{C}$, et al. Elimination of atrioventricular nodal reentrant tachycardia using discrete slow potentials to guide application of radiofrequency energy. Circulation 1992;85:2162-75.

14 McGuire MA, de Bakker JMT, Loh P, Thibault B, Vermeulen JT Atrioventricular junctional tissue: discrepancy between histological and electrophysiological characteristics. Circulation 1996;94:571-7.

15 Jazayeri MR, Sra JS, Hempe S, Deshpande S, Blanck S, Blanck Z, et al. Electrophysiologic spectrum of atrioventricular nodal behaviour in patients with atrioventricular nodal reentrant tachycardia undergoing selective fast or slow pathway ablation. $₹$ Cardiovasc Electrophysiol 1993; 4:99-111.

16 De Bakker JMT, Coronel R, McGuire MA, Vermeulen JT, Opthof T, Tasseron $\mathrm{S}$, et al. Slow potentials in the atrioventricular junctional area of patients operated on atrioventricular node tachycardias and in isolated porcine hearts. $f$ Am Coll Cardiol 1994;23:709-15.

17 Racker DK. Sinoventricular transmission in $10 \mathrm{mM} \mathrm{K}^{+}$by canine atrioventricular nodal inputs: superior atrionodal bundle and proximal atrioventricular bundle. Circulation 1991;83:1738-48.

18 Medkour D, Becker AE, Khalite K, Billette J. Anatomical and functional characteristics of a slow posterior pathway in the rabbit atrioventricular node [abstract]. PACE 1997;20:1174. 